\title{
CD8 malignant proliferation in association with human $T$ cell lymphotropic Virus 1 infection: a case report
}

\author{
Huseini Kagdi ${ }^{*}$, Aileen Rowan², Fiona Child ${ }^{3}$, Edwardo Calonje ${ }^{4}$, Mufaddal Moomin ${ }^{5}$, Maria Antoinietta Demontis ${ }^{1}$, \\ Charles Bangham², Graham Taylor ${ }^{1}$, Paul Fields ${ }^{6}$
}

From 17th International Conference on Human Retroviruses: HTLV and Related Viruses

Trois Ilets, Martinique. 18-21 June 2015

Adult $\mathrm{T}$ cell leukaemia/lymphoma (ATL) is a predominantly CD4+ T cell neoplasia caused by human $\mathrm{T}$ cell lymphotropic Virus 1 (HTLV-1) infection. A few cases of CD8+ ATL have been reported but its existence has been debated. An Afrocaribbean female presented to the dermatology clinic with widespread papulo-nodular rash. HTLV-1 infection was detected by serology. Skin biopsy showed dense dermal infiltration by mainly CD8+ T cells which also expressed CD2, CD3, CD5, CD7 and occasionally CD25. Further investigations showed a mild lymphocytosis $(4.4 \times 106 / \mathrm{L})$, circulating flower cells, absolute CD4+ count $1247 \times 106 / \mathrm{L}$ (28.3\% of lymphocytes), absolute CD8+ count x $2617 \times 106 / \mathrm{L}$ (59.8\% of lymphocytes), LDH 241 U/L (NR 135 - 214), Calcium $2.7 \mathrm{mmol} / \mathrm{L}$ (NR 2.2 - 2.6) but with increased serum PTH level. HTLV-1 proviral load (PVL) in peripheral blood mononuclear cells was $46 \%$. PET/CT scan demonstrated FDG avid lymph nodes above and below the diaphragm. Axillary lymph node core biopsy showed CD20+ B cells nodules admixed with mainly small-to-medium sized $\mathrm{T}$ cells and a small population of large $\mathrm{T}$ cells. The small lymphocytes were mainly CD8 $+\mathrm{T}$ cells (also expressed CD2, CD3, CD5, and CD7 whereas the large cells expressed CD8, CD25 and CD30. Fewer than 5\% expressed Ki67 (MIB-1). TCR clonality studies by PCR revealed expansion of an identical clone in all three compartments (skin, lymph node and blood). Detailed immunophenotyping on peripheral blood demonstrated a single dominant TCR v $\beta 1+$ clone $(>90 \%$ of total CD8 T cells) which was $\mathrm{CD} 3+, \mathrm{CD} 7+, \mathrm{CCR} 4+, \mathrm{CD} 25$ low and, TSCL-1-. In summary we report a malignant CD8+ clone with atypical immunophenotype in a patient with high PVL. To confirm a working diagnosis of CD8+ ATL high throughput sequencing of each proviral integration sites is underway.

\section{Authors' details}

'Section of Retrovirology and GU medicine, Department of Medicine, Imperial College London, London, England, W2 1PG, UK. ${ }^{2}$ Section of Virology, Department of Medicine, Imperial College London, London, England, W2 1PG, UK. 'Department of Dermatology, St John's Institute of Dermatology, London, England, SE1 7EH, UK. ${ }^{4}$ Department of Dermatopathology, St John's Institute of Dermatology, London, England, SE1 7EH, UK. ${ }^{5}$ Department of Histopathology, Guy's and St Thomas' Hospitals, Guy's \& St Thomas' Foundation Trust, Westminster Bridge Road, London SE1 7EH, UK. 'Department of Haematology Guy's and St Thomas' Hospitals, Guy's \& St Thomas' Foundation Trust, Westminster Bridge Road, London SE1 7EH, UK.

Published: 28 August 2015

doi:10.1186/1742-4690-12-S1-P68

Cite this article as: Kagdi et al:: CD8 malignant proliferation in association with human T cell lymphotropic Virus 1 infection: a case report. Retrovirology 2015 12(Suppl 1):P68.

\footnotetext{
* Correspondence: hkagdi@imperial.ac.uk

'Section of Retrovirology and GU medicine, Department of Medicine,

Imperial College London, London, England, W2 1PG, UK

Full list of author information is available at the end of the article
} 